\title{
Rés negras, juízes brancos: Uma análise da interseccionalidade de gênero, raça e classe na produção da punição em uma prisão paulistana
}

\author{
Prisiones negras, jueces blancos: Género, raza e clase en la distribución \\ de la punición en el sistema de justicia penal paulista
}

\author{
Prisons black, white judges: Gender, race and class in the \\ distribution of punishment in the criminal justice system paulista
}

\footnotetext{
* Advogada. Candidata a PhD e Mestra em Ciências Sociais, na área de Antropologia pela PUC/SP. Pesquisa desde 2009, sobre Gênero-Raça-Prisão. Membra efetiva do Grupo de Estudos «Interseccionalidades» entre Brasil/Colômbia/Bolívia, com foco em pesquisas sobre violências raciais nas Américas. dinaalves@adv.oabsp.org.br

** Artigo científico que apresenta os resultados da investigação intitulada «Rés negras, juízes brancos: uma análise da interseccionalidade de gênero, raça e classe na produção da punição em uma prisão paulistana» desenvolvida pela autora para obter o título de mestre em ciências sociais nos anos de 2013/2015, pela Universidade Pontifícia Católica de São Paulo, sob orientação de Profa. Dra. Josildeth Gomes Consorte, a quem agradeço imensamente a parceria bem sucedida e intermináveis discussões sobre a temática; Agradeço ainda a dedicada revisão dos pares anônimos durante o processo da Revista CS, e, por fim, ao Prof. Dr. Jaime Alves, Universidade da Cidade de Nova York (CUNY/CSI), pela contribuição e disposição de debater se comprometer, incansavelmente, com este tema. Artículo de investigación recibido el 29-05-2016 y aceptado 17-02-2017.
} 


\section{Cómo citar}

ALVES, D. (2017). Rés negras, juízes brancos: uma análise da interseccionalidade de gênero, raça e classe na produção da punição em uma prisão paulistana. Revista CS, 21, pp. 97-120. Cali, Colombia: Facultad de Derecho y Ciencias Sociales, Universidad Icesi.

DOI: http://dx.doi.org/10.18046/recs.i21.2218 


\section{Resumo}

Resumen

Abstract

Este artigo tem como objetivo oferecer uma análise interseccional dos atributos de gênero, raça e classe na distribuição da punição, no sistema criminal paulista. Para tanto foram analisadas sentenças judiciais e entrevistas com mulheres negras encarceradas, no ano de 2015. O trabalho sugere que o sistema de justiça penal funciona como instrumento de dominação racial, pois é na sua administração que se manifesta de forma explícita a intersecção dos eixos de vulnerabilidade -delineados por raça, classe e gênero-na produção de categorias de indivíduos puníveis.

\section{PALAVRAS-CHAVES:}

Gênero | Raça | Justiça penal | Interseccionalidade

Esta investigación tiene como objetivo ofrecer un análisis interseccional de los atributos de género, raza y clase en la distribución de la pena, en el sistema criminal de Sao Paulo. Por tanto, los fallos judiciales y entrevistas con las mujeres negras en prisión, fueron analizadas en el año 2015. El trabajo sugiere que el sistema de justicia penal funciona como instrumento de dominación racial, ya que en su administración se manifesta de forma explícita la intersección de los ejes de vulnarabilidad-atravesados por raza, clase y género- en la produccón de las categorías de sujetos punibles.

\section{PALABRAS CLAVE:}

Género | Raza | Justicia criminal | Interseccionalidad

This paper aims to offer an intersectional analysis of gender attributes, race and class in the distribution of punishment, in São Paulo's criminal system. For both court decisions and interviews with imprisoned black women were analyzed in the year 2015. The work suggests 
that the criminal justice system works as racial domination instrument, because it is in its administration that manifests explicitly the intersection of the axes vulnerability-outlined by race, class and gender-in the production of categories of individuals punishable.

\section{KEYWORDS:}

Gender | Breed | Criminal justice | Intersectionality 


\section{Introdução}

No momento em que o juiz a sentenciou como traficante de drogas e decretou a sentença de oito anos de reclusão, dona Joana, 49 anos de idade e mãe de seis filhos, carroceira, não pensou duas vezes e explodiu: «se eu fosse traficante não estaria banguela». Pode a vida de uma mulher negra -pobre, carroceira e vendedora de drogas- nas mãos de um juiz homem -branco, classe média alta- nos ajudar a entender o regime de dominação racial presente no sistema de justiça penal no Brasil? Cada vez mais marginalizadas do acesso às esferas de produção, de consumo e de direitos de cidadania, mulheres negras figuram na economia ilegal do tráfico de drogas como vendedoras, mulas ou simplesmente consumidoras. Suas experiências podem ser entendidas a partir do que a socióloga norte-americana Julia Sudbury tem chamado de «feminizacão da pobreza e da punição», isto é, de como as vulnerabilidades sociais, a criminalização e a punição fazem parte do mesmo processo de subordinação racial das mulheres negras. Dona Joana tem a trajetória de vida prisional intimamente relacionada com este processo e o seu encontro com o Estado penal está longe de ser uma exceção. Segundo o Departamento Penitenciário Nacional (DEPEN), existem atualmente 11.853 mulheres encarceradas no estado de São Paulo, o que equivale a 5,76\% da população carcerária estadual e a 35,6\% da população carcerária feminina nacional. Entre elas, as mulheres pardas representam $28,73 \%$ e as negras, $11,8 \%$. A maioria das presas é condenada por crimes relacionados ao tráfico de drogas e contra a propriedade privada (DEPEN, 2014).

Este artigo se propõe a responder à seguinte pergunta: o que o encarceramento desproporcional de mulheres negras tem a nos dizer sobre o padrão de relações raciais no Brasil contemporâneo? O que tal prática revela sobre o lugar histórico ocupado pelas mulheres negras em nossa formação (como escravas, empregadas domésticas, moradoras das favelas) e no imaginário social brasileiro?

$\mathrm{O}$ artigo está organizado da seguinte maneira: primeiro contextualizo a experiência das mulheres negras no boom prisional brasileiro e paulista da última década baseada em dados estatísticos do Infopen (Sistema Integrado de Informações Penitenciárias), ou seja, o contexto no qual história como a de D. Joana se encontram. Segundo, apresento uma perspectiva feminista negra como uma estratégia teórica alternativa para localizar e interpretar a distribuição da punição no sistema de justiça penal paulista. Terceiro, analiso as histórias de vida de três mulheres negras condenadas por tráfico de drogas na capital paulista. Antes de apresentar o contexto penal em que este artigo se situa, é necessária uma breve nota metodológica. 


\section{Material e método}

A pesquisa foi realizada na Penitenciária Feminina de Sant'Ana (PFS), na cidade de São Paulo, entre os meses de agosto e dezembro de 2014. A metodologia se baseou em entrevistas semiestruturadas com 10 mulheres negras, trabalho etnográfico (observação participante), consultas a processos judiciais e prontuários criminológicos. As entrevistas ocorreram informalmente, sem gravador de voz, apenas com anotações no diário de campo. Dada a precariedade do espaço da pesquisa, muitas vezes, não fazia anotações ali, na frente das entrevistadas. Ao sair da penitenciária, sentava no paralelepípedo na sua entrada e anotava as informações mais importantes, aproveitando cada frase e lembrando cada emoção que havia presenciado e sentido junto com as mulheres entrevistadas. Finalmente, a pesquisa assume uma perspectiva da antropologia ativista que, embora reconheça a importância do distanciamento saudável do «objeto» de pesquisa, busca intervir na realidade estudada a partir do engajamento crítico e do compromisso ético com os indivíduos com os quais se produz o conhecimento codificado em linguagem acadêmica (FREIRE, 96).

Deste modo, baseada na própria experiência como mulher, negra, oriunda da periferia, busquei, nesta alternativa metodológica, os subsídios teóricos para uma análise da intersecção de gênero, raça e classe. Embora limitada, uma vez que o engajamento político também afeta a maneira de ver e interpretar os fenômenos sociais, essa perspectiva abre novas possibilidades de interpretação da realidade estudada (HALE, 20O1; VARGAS 2008; GROSFOGUEL, 2007; SADENBERG, 2002). No que diz respeito ao sistema de justiça criminal, a pesquisa engajada na perspectiva da experiência negra pode, por exemplo, contribuir de forma crucial no entendimento de que o Brasil, ao contrário do que se quer fazer crer, não é uma exceção no que diz respeito ao complexo industrial prisional global. Entender a vida das mulheres negras encarceradas requer do pesquisador questionar os mitos sobre criminalidade e ordem produzidos pelos discursos estatais. As trajetórias de vida das mulheres descritas aqui são centrais para a leitura do «lugar» e do «não lugar» da mulher negra encarcerada: seus encontros com a justiça criminal; as torturas sofridas no momento da prisão e no cumprimento da pena; a negação aos benefícios penais sem motivação judicial e a transmissão intergeracional da pena aos seus familiares. Suas experiências no interior do sistema são «textos» que nos orientam a pensar na produção de corpos puníveis, não como um exercício retórico, mas como uma necessidade urgente para entendermos como a mulher negra veio a ocupar uma posição paradigmática no Brasil contemporâneo. 


\section{A cor e o gênero das prisões}

O Brasil possui hoje uma população prisional de 622.202, ficando atrás apenas dos Estados Unidos, da China e da Rússia. No que diz respeito ao perfil etário dessa população, observa-se que a proporção de jovens é maior no sistema prisional que na população em geral. Ao passo que $56 \%$ da população prisional é composta por jovens, essa faixa etária compõe apenas $21,5 \%$ da população total do país. Deste total, $67 \%$ são negros (DEPEN, 2014). O número de pessoas privadas de liberdade em 2014 era 6,7 vezes maior do que em 1990. No que diz respeito à questão de gênero, o Brasil conta com uma população prisional feminina de 37.380 presas. No período de 2000 a 2014 , o aumento da população feminina foi de $567,4 \%$, enquanto a média de crescimento masculina, no mesmo período, foi de $220,20 \%$, refletindo, assim, a curva ascendente do encarceramento em massa de mulheres. A maioria absoluta da população prisional brasileira é negra em todos os estados da federação. Em termos proporcionais, contudo, observa-se que a sobrerrepresentação dos negros na população prisional é mais acentuada na região Sudeste com $72 \%$. Nessa região, os negros representam apenas $42 \%$ da população total.

São Paulo possui o maior número de presos no país, ocupa a quarta posição na taxa de encarceramento de jovens negros e a segunda maior taxa de adolescentes em medidas socioeducativas de internação e semiliberdade. Nos últimos dez anos (2006-2016), o estado registrou um boom em seu sistema prisional, com a construção de novos presídios, aliada a uma política de encarceramento em massa que resultou na prisão de $\mathbf{2 1 4 . 8 4 3}$ pessoas (Tabela 1). São Paulo tem também a maior população absoluta de mulheres encarceradas, respondendo por $39 \%$ do total de mulheres presas no país.

TABELA 1 | População prisional do estado de São Paulo entre 2007 e 2014, por sexo.

\begin{tabular}{|l|c|c|c|c|c|c|c|c}
\hline Sexo & 2007 & 2008 & 2009 & 2010 & 2011 & 2012 & 2013 & 2014 \\
\hline Homem & 135.078 & 137.702 & 146.910 & 155.185 & 164.298 & 179.552 & 194.113 & 200.033 \\
\hline Mulher & 6.531 & 6.820 & 7.605 & 8.491 & 9.762 & 11.276 & 11.896 & 14.810 \\
\hline TOTAL & $\mathbf{1 4 1 . 6 0 9}$ & $\mathbf{1 4 4 . 5 2 2}$ & $\mathbf{1 5 4 . 5 1 5}$ & $\mathbf{1 6 3 . 6 7 6}$ & $\mathbf{1 7 4 . 0 6 0}$ & $\mathbf{1 9 0 . 8 2 8}$ & $\mathbf{2 0 6 . 0 0 9}$ & $\mathbf{2 1 4 . 8 4 3}$ \\
\hline
\end{tabular}


Note-se que, no período analisado, enquanto a taxa de encarceramento masculino aumentou em 48\%, a taxa de mulheres encarceradas teve um aumento de $127 \%$, evidenciando o crescimento proporcional das mulheres no sistema prisional. Ao traçar o perfil das 14.810 mulheres encarceradas é possível visualizar uma linha de cor e de gênero nas prisões paulistanas: as negras compõem 67\% do total; as jovens entre 18 e 29 anos representam 50\%; as mulheres que não concluíram o ensino fundamental, 50\%; e as que foram condenadas com penas de até oito anos de reclusão compõem o universo de $63 \%$. A participação delas nas estatísticas criminais envolvendo os dois gêneros tem o menor número nos crimes contra a vida, computando $7 \%$ dos casos; nos crimes contra o patrimônio o universo é de $15 \%$; e nos crimes de tráfico de drogas o número salta para 63\% (DEPEN, 2014).

Num estudo mais vertical sobre o perfil dessas mulheres, o Projeto «Tecer Justiça» desenvolvido por entidades de direitos humanos em São Paulo, realizou uma pesquisa em 2010 e 2011 no Centro de Detenção Provisória I de Pinheiros e Penitenciária Feminina de Sant'Ana e o estudo confirmou o vínculo das mulheres com crimes relacionados a drogas. Dos homens atendidos, $41 \%$ foram presos por furto, $36 \%$ por roubo e $16 \%$ por tráfico. Entre as mulheres, o furto corresponde a 39\%, uma porcentagem semelhante à dos homens; já em relação ao roubo e ao tráfico, a situação se inverte: o roubo cai para $17 \%$, enquanto o tráfico sobe para $39 \%$. Considerando que o roubo é um crime com um componente maior de violência, veremos que a tendência é os homens estarem mais próximos de crimes envolvendo violência, e as mulheres mais próximas de crimes envolvendo drogas (CERNEKA, 2013).

Embora a população carcerária feminina seja historicamente menor do que a masculina, pode-se dizer que há uma feminização da punição, principalmente no que diz respeito a crime de tráfico de drogas. A maioria delas ocupa uma posição coadjuvante no crime, realizando serviços de transporte de drogas e pequeno comércio; muitas são usuárias, sendo poucas as que exercem atividades de gerência do tráfico. Elas são moradoras da periferia, responsáveis pela provisão do sustento familiar, com baixa escolaridade, oriundas de extratos sociais desfavorecidos economicamente e exerciam atividades de trabalho informal em período anterior ao aprisionamento.

Apesar das mulheres presas serem objeto de crescente interesse entre pesquisadores do sistema penitenciário nacional, as mulheres negras não aparecem em suas discussões, ainda que constituam o principal grupo de presas no país. Alguns trabalhos têm mostrado que as mulheres, de modo geral, possuem uma vulnerabilidade específica, marcada por sua condição de gênero em uma sociedade estruturada a partir de desigualdades entre homens e mulheres (BRAUNSTEIN, 2007; PRADO, 2003). Apesar dos estudos e das estatísticas apresentadas ajudarem a entender a dimensão de gênero nas prisões -uma vez que eles têm o mérito de desmasculinizar as narrativas sobre o universo prisionalestes estudos têm se revelado insuficientes no que diz respeito à especificidade da mulher 
negra. Ao apresentar uma análise interseccional de como raça, gênero e classe social produzem a categoria «mulher encarcerada», esta reflexão busca preencher esta lacuna. Para isso, tomo como ponto de partida a perspectiva feminista negra desenvolvida por Lélia Gonzalez (1983), Sueli Carneiro (1995) e Kimberley Crenshaw (1995), em suas análises daquilo que se convencionou chamar de «matriz da dominação».

De acordo com as autoras acima citadas, os processos de produção de vulnerabilidade social e de dominação não podem ser entendidos sem se levar em conta a intersecção de raça, gênero e classe social. O interesse teórico e epistemológico de articular classe, raça e gênero, para além de analisar as diferenças entre homens e mulheres, mas entender o universo prisional e as desigualdades que norteiam as mulheres negras encarceradas e os juízes brancos que sentenciam as decisões desfavoráveis a elas. A condição da categoria «mulher negra encarcerada» oferece, portanto, possibilidades não apenas para diagnosticar as suas especificidades, como também permite desenvolver uma metodologia de análise que considere as interfaces de tais categorias na produção de regimes de poder e na busca de alternativas de resistência. Daí, a interseccionalidade se apresenta como instrumento de luta política para entender a judicialização das mulheres negras em São Paulo que reflete o modelo de relações raciais do país, e ainda oferece possibilidades de descentralizar (ou complexar) os estudos sobre as prisões, que têm privilegiado a perspectiva de classe social em detrimento de uma abordagem mais ampla e condizente com a realidade racial brasileira (ver, por exemplo, BRAUSTEIN, 2007; CERNEKA, 2009; PASSETTI, 2006).

\section{Direitos humanos, para quem?}

Não é de hoje que as organizações internacionais de direitos humanos têm chamado a atenção do mundo para a realidade degradante das prisões brasileiras. Casos como o de Barbara Oliveira de Souza, do presídio Talavera Bruce, no Rio de Janeiro, que foi deixada no isolamento (castigo) com nove meses de gravidez e deu à luz sem assistência médica; ou ainda a contenção física de mulheres presas durante o parto com o uso de algemas nos quatros membros; ou ainda as decapitações dos presos no interior do Complexo de Pedrinhas, são apenas exemplos da relativização da vida dos considerados «cidadãos/ cidadãs indesejáveis» (ONU, 2016).

Em 2010, a organização Human Rights Watch elaborou denúncia com registro de 64 casos de tortura praticado por agentes penitenciários e policiais civis/militares no Brasil. As denúncias envolvem espancamentos, agressões físicas, uso de choques elétricos no corpo, sufocamento com sacos plásticos, violência sexual, psicológica, afogamentos em privadas com fezes, ingestão de parafina, entre outros. O relatório denunciou que os exames de corpo de delito de presos que denunciam abusos são tardios, realizados 
de forma superficial ou na presença de policiais torturadores. Os exames apreendidos pela organização não contêm fotografias das lesões, impressões digitais dos presos e outras informações essenciais à investigação. ${ }^{1} \mathrm{~A}$ ONU (Organização das Nações Unidas) também traz graves denúncias de casos de violações dos direitos humanos nas prisões brasileiras: superlotação das unidades, em alguns casos, com quase três vezes mais que sua capacidade; recorrentes casos de tortura na detenção e no interrogatório, condições caóticas dentro das instalações, com grande impacto nas condições de vida dos detentos e no acesso à assistência jurídica, aos cuidados com a saúde, ao apoio psicossocial, a oportunidades de trabalho e estudo; frequentes usos de spray de pimenta, gás lacrimogêneo, bomba de ruído e bala de borracha; uso de armamento pesado, incluindo fuzis, escopetas, espingardas e pistolas pelos funcionários das prisões. Consta neste relatório que «negros enfrentam risco significativamente maior de encarceramento em massa, abuso policial, tortura e maus-tratos, negligência médica e recebem sentenças maiores que os brancos pelo mesmo crime e a discriminação na prisão - sugerindo alto grau de racismo institucional» (ONU, 2016).

Apesar de o Brasil ser signatário de diversas convenções internacionais contra a tortura persistem as sistemáticas violações de direitos humanos da população negra e pobre, com as práticas cotidianas de extermínios desses grupos. De fato, a justiça penal é um lugar privilegiado de reprodução das desigualdades raciais. Nela, as categorias «crime», «criminoso», «puníveis», «inocentes», «vítimas» não são categorias neutras, elas dão sentido aos entendimentos de raça que governa as relações raciais no Brasil (CIRINO, 2006). Uma perspectiva crítica de raça diria também que nossa posição social, nosso pertencimento racial e nossos privilégios múltiplos definem cidadãos puníveis e inocentes.

\section{Feminização da pobreza e racialização da punição}

No dia 16 de março de 2014, após operação da Polícia Militar numa favela do Rio de Janeiro, o corpo negro e quase sem vida de Claudia Ferreira da Silva, de 38 anos de idade, empregada doméstica, foi arrastado pelas ruas. ${ }^{2}$ Talvez o/a leitor/a se pergunte: o que tem a ver a morte de uma mulher na favela com o encarceramento em massa? $\mathrm{O}$

1. A Pastoral Carcerária e o Instituto Terra, Trabalho e Cidadania - ITTC têm feito denúncias históricas sobre revistas vexatórias, agressões físicas, negações de benefícios penais, superlotações em celas, maus tratos por parte dos agentes penitenciários, partos em celas sem assistência médica, violências sexuais e psicológicas, principalmente contra as mulheres presas.

2. Claudia foi baleada no pescoço e nas costas, foi colocada no porta-malas da viatura policial supostamente para ser levada ao hospital. No caminho, seu corpo rolou do porta-malas e, preso por um pedaço de roupa, foi arrastado pelo asfalto por mais ou menos 250 metros, sem que os policiais da viatura dessem atenção aos apelos de outros motoristas e pedestres. 
ocorrido com Claudia ajuda-nos a entender a relação senzala-favela-prisão situando-a no continuum penal que marca a transição entre escravidão e democracia (DAVIS, 2009; ALVES, 2014; BATISTA, 2O02; ZAFARONI 2003). Ser negra, pobre e mulher demarca a posição de vulnerabilidade extrema na sociedade brasileira. Sueli Carneiro tem se referido à invisibilidade da mulher negra com a expressão «a última da fila depois de ninguém». Ou seja, as mulheres negras ocupam um lugar de total vulnerabilidade na pirâmide social brasileira. A atual situação social da mulher negra é fruto de raízes históricas, cuja ideologia ainda determina o seu «lugar» e o seu «não lugar»-ontem mucamas e amas de leite, hoje empregadas domésticas (CARNEIRO, 1995).

O trabalho doméstico foi e continua sendo a principal ocupação das mulheres negras. No passado, elas ocupavam as mais variadas atividades: lavadeiras, cozinheiras, babás, amas de leite, mucamas. O fim do sistema escravocrata trouxe novos arranjos para que as mulheres negras continuassem a exercer as mesmas atividades. Elas deixaram de ser escravas domésticas para ser empregadas domésticas (PEREIRA, 2011). O trabalho como empregada doméstica não era apenas uma porta de entrada para o mercado de trabalho, mas a única forma possível de ocupação oferecida a elas. Não há no Brasil outra imagem tão simbólica do período escravocrata como a imagem de uma mulher negra, vestida de uniforme branco, encerando os vidros de janelas de condomínios de luxo ou a imagem de uma mulher negra, uniformizada, empurrando um carrinho de bebê de uma família branca. As mulheres negras são maioria no emprego doméstico, têm escolaridade menor e são menos remuneradas. ${ }^{3}$

Entre as trabalhadoras com carteira assinada também existe diferença. O percentual é de $33,5 \%$ das mulheres brancas e $28,6 \%$ das mulheres negras. Isso reflete diretamente no salário que elas recebem: $\mathrm{R} \$ 766,6$ das brancas contra $\mathrm{R} \$ 639,0$ das negras, valor inferior ao salário-mínimo. ${ }^{4}$ Entender esse continuum entre, escravidão e emprego doméstico, e o «lugar» paradigmático ocupado pelas mulheres negras na sociedade brasileira é ter em mente que o período pós-abolição demarcou a histórica continuidade da sujeição, subordinação e desumanização das mulheres negras, hoje aprisionadas nas cozinhas das madames brancas. Reatualizou, ainda, a divisão sexual do trabalho hierarquizado a partir de representações sociais -empregadas domésticas, moradoras das favelas/periferias, escravas, babás, amas de leite, mulatas etc. - do «lugar» histórico ocupado por elas. Se a cozinha é o lugar de representação colonial por excelência, as

3. Apenas recentemente foi promulgada a PEC das domésticas e a Lei n. 12.964/2014, que obriga os empregadores domésticos a registrar seus empregados sob pena de pagamento de multa.

4. As projeções do IPEA são pessimistas: a renda média nacional da população negra só será equiparada à renda da população branca no ano de 2040 . Hoje, a remuneração média dos negros é $45 \%$ menor que a dos brancos. Em São Paulo, por exemplo, negros ganham em média de R \$3,99 por hora de serviço, enquanto os brancos recebem $R$ \$7,33. Os negros entram no mercado de trabalho mais cedo e saem mais tarde: na exploração de mão de obra infantil, as crianças negras, com idade entre 5 e 9 anos, são 69,5\% das vítimas (PNAD, 2007). 
prisões modernas têm o «privilégio» de ser o lugar onde se materializam as estruturas hierárquicas impostas pela lógica racial da desumanização do corpo negro. A desumanização na cozinha e na prisão abre caminho para a criminalização pelo Estado penal.

Embora o Estado brasileiro tenha sempre ocupado lugar de destaque na produção das condições históricas desfavoráveis ao desenvolvimento social da mulher negra, a pesquisa mostrou que é na administração da justiça que se manifesta, de forma explícita, a intersecção dos eixos de vulnerabilidade -delineados por raça, classe e gênero- na produção de categorias de indivíduos puníveis. Considerar a vigilância ostensiva e a seletividade penal a que estão submetidas as mulheres negras é muito importante aqui porque os intérpretes da lei (sejam eles policiais, promotores, juízes, advogados, legisladores, administradores, defensores públicos e demais servidores públicos da justiça penal) reproduzem, disseminam e sustentam um regime racial de «produção de verdade» (FOUCAULT, 2004), que favorece a produção de provas e a atuação policiva voltada à ampliação do poder penal e ao encarceramento em massa de indivíduos considerados «suspeitos».

Com efeito, no contexto norte-americano, Ângela Davis (2009) argumenta que o encarceramento em massa das mulheres negras se deve à desestabilização do Estado Social, que, apesar de não ter fornecido uma solução eficaz aos problemas das mães solteiras, desempregadas e com pouca ou nenhuma oportunidade profissional, fornecia uma rede de proteção aos mais pobres. O Estado racial contemporâneo, pode-se dizer, não se converte apenas em um ente incapaz de atender direitos básicos de cidadania, mas também em um Robin Hood às avessas. Também Wacquant (2001) sugere que a ampliação abrupta do número de presos está profundamente relacionada à diminuição do Estado social, marcada por políticas de seguridade social mínimas, perseguição sistemática aos pobres e ampliação abrupta do estado penal. Enquanto o Estado neoliberal se ausenta das políticas sociais, ele passa a governar por meio de políticas de controle da criminalidade que têm como sua razão de ser a criminalização de grupos racializados. A prisão tem sido a solução punitiva para uma gama completa de problemas sociais para os quais o estado tem sido incapaz de oferecer respostas. Feministas abolicionistas têm alertado para o que chamam de «farra do aprisionamento»: em vez de construírem moradias, jogam os sem-tetos na cadeia. Em vez de desenvolverem o sistema educacional, jogam os analfabetos na cadeia. Jogam na prisão os desempregados decorrentes da desindustrialização, da globalização do capital e do desmantelamento do Estado de bem-estar social (DAVIS, 2009).5

\footnotetext{
5. De acordo com Angela Davis, quando se considera a dimensão em que as prisões obtêm lucro enquanto produzem meios de mutilar e matar seres humanos, e devorar recursos públicos, as semelhanças básicas tornam-se evidentes. As prisões não são mais nicho menor para as indústrias; a indústria da punição está no radar de incontáveis corporações nas indústrias de manufaturas e de serviços. Os presídios são identificados por seu potencial de consumidores e por seu potencial de mão de obra barata (DAVIS, 2009, p. 46).
} 
É neste sentido que podemos considerar o ordenamento jurídico brasileiro como uma (re)atualização da ordem escravocrata. Que tal sistema patriarcal-punitivo tinha (e tem) no corpo da mulher negra um de seus principais alvos pode ser ilustrado não apenas na experiência de mulheres empregadas domésticas negras aprisionadas nas cozinhas das elites brancas, mas também nas estatísticas prisionais que apontam aumento consistente no número de mulheres negras presas. Como sustentou a pesquisa, o lugar social que as mulheres negras ocupam na sociedade brasileira é refletido nas decisões desfavoráveis a elas no sistema de justiça penal. A condição das mulheres negras brasileiras também reflete o que Julia Sudbury (2005) tem chamado de «feminização da pobreza e da punição» no mundo contemporâneo. Para ela, embora o «complexo industrial prisional global» seja majoritariamente composto de homens negros, as mulheres negras, dada a sua condição vulnerável na economia neoliberal, têm cada vez mais sido objeto do Estado Penal.

A tese da feminista negra estadunidense é importante no contexto brasileiro porque, embora os homens representem mais de $90 \%$ da população prisional, as mulheres negras são, proporcionalmente, o grupo que mais cresce. Se o Estado neoliberal pode ser caracterizado a partir do que Wacquant (2001) conceituou como «simbiose mortal» entre raça, pobreza e punição, suas consequências para as mulheres negras têm sido ainda mais desastrosas. Alves (2014), ao retratar a discussão sobre gênero, raça, pobreza e punição, sugere que o número crescente de mulheres negras presas como «mulas» no tráfico de drogas é um sintoma do regime racializado de dominação patriarcal do qual o Estado penal é a sua maior expressão. $\mathrm{O}$ autor propõe uma leitura da participação cada vez maior de mulheres negras no microtráfico de drogas como uma outra dimensão do regime racializado de cidadania, em que as mulheres negras aparecem como cidadãs de segunda categoria, ou não cidadãs.

A relação entre regime punitivo e escravidão no Brasil amplia as análises de Michael Foucault sobre o nascimento das prisões. A tese central de Foucault é a de que as prisões deram nascimento a uma série de mecanismos de disciplina que constituem o que o autor chamou de «tecnologia política dos corpos» (FOUCAULT, 1987). Embora o autor situe as prisões no «novo paradigma de poder» da modernidade, (que substituiu o espetáculo soberano da morte), quando considerada a condição negra, parece mais pertinente argumentar que a prisão moderna funda um tipo de direito penal que tem no corpo negro o seu alvo e na espetacularização da punição sua racionalidade. Com isso não quero argumentar que as mulheres negras sejam as únicas vitimas do encarceramento, mas apresentar uma nova perspectiva que considere a prisão como espaço negro e como expressão da banalidade do poder de soberania sobre corpos criminalizados. A fim de entendermos o «lugar» paradigmático das mulheres negras no sistema penal, se torna igualmente importante analisarmos o «lugar» racialmente privilegiado ocupado pelos juízes, bem como suas decisões desfavoráveis a elas. 


\section{Juízes brancos / Rés negras}

De acordo com o Censo dos Magistrados, realizado pelo Conselho Nacional de Justiça (CNJ), em 2013, 64\% dos juízes são homens e 82\% são ministros dos tribunais superiores. No quesito cor/etnia: $84,5 \%$ são brancos, $15,4 \%$ são pretos/pardos, o, $1 \%$, indígenas. A idade média de juízes é de 45 anos para desembargadores e ministros comuns, e de 42 anos para os juízes da Justiça Federal. O que os dados acima nos permitem afirmar é a persistência de uma estrutura a que Rita Segato (2007), apropriadamente, se refere como a «colonialidade da justiça». Segundo a autora, apesar da transição de colônia para república, as instituições de justiça penal na América Latina continuam reproduzindo e ecoando as relações sociais do regime escravocrata. Mesmo na ausência de leis explicitamente racistas, a lei se constituiu entre nós não como garantia de direitos, mas como punição dos grupos historicamente situados à margem da cidadania. Para Segato (2007), o sistema de justiça criminal na América Latina tem a raça como seu princípio organizador no processo de encarceramento e na história de dominação colonial que perdura até os dias atuais.

Reconhecer a existência da categoria «raça» como uma realidade social e ideologicamente construída -que tem impacto direto na vida das mulheres negras- é levar em consideração que determinados grupos raciais estão mais vulneráveis à punição estatal mesmo quando a punição não é articulada em termos da seletividade racial. Neste sentido, Raul Zafaronni (2003) e Nilo Batista (2002) têm mostrado que as matrizes do sistema de justiça penal brasileiro são fundamentalmente influenciadas por uma concepção de crime e de castigo baseada na punição do corpo negro. Na história brasileira, os senhores de engenho detinham poder de vida e de morte sobre seus escravizados e os ordenamentos jurídicos da colônia pouco importavam, dada a condição mercantil do escravo. ${ }^{6}$

\footnotetext{
6. O Direito Penal, herdeiro direto das teorias lombrosianas, reproduz um léxico que revela suas origens eugênicas. Os jargões jurídicos «personalidade desajustada e perigosa», "personalidade voltada para o crime», «personalidade perigosa», constantes nas sentenças criminais (analisadas na pesquisa de mestrado) refletem a presença persistente de tais ideologias. Do mesmo jeito, as posturas comuns de policiais militares na abordagem do «suspeito-padrão» não deixam dúvidas de que recai a pretos e pobres o «tipo ideal» do criminoso nato. Um recente memorando interno da Polícia Militar de Campinas, orientando os policiais militares a abordarem jovens negros nas blitz, é apenas uma destas dimensões. A persistência dessas teorias também pode ser observada no resultado de pesquisa realizada pelo Núcleo de Estudos da Violência da USP (NEV), no ano de 2011, sobre as «atitudes suspeitas» nos flagrantes realizados pela Polícia Militar de São Paulo. O estudo revelou que os policiais militares se baseiam em um «conhecimento racial» para realizar os flagrantes por acusação de tráfico de drogas. Durante três meses de pesquisa, nenhum financiador do tráfico foi preso em flagrante, nenhum acusado advindo da classe média foi mantido preso. Isso evidencia que, apesar da mudança legislativa, os operadores não repensaram suas práticas de forma a torná-las mais igualitárias e eficientes. O foco no tráfico varejista e nas classes mais pobres impede que os operadores tomem conhecimento do verdadeiro mundo do tráfico que está pulverizado por todas as regiões da cidade e todas as classes sociais (CERNEKA,2O1O).
} 
O poder despótico dos senhores de escravizados inaugurou uma espécie de estado de exceção no qual a lei aparece para os negros sempre como punição, nunca como garantia de direitos (ADORNO, 1995). Argumento semelhante tem sido sistematicamente desenvolvido por Ângela Davis (2003), para quem as modernas prisões são nada mais do que uma réplica do regime escravocrata. Davis questiona a «democracia penal» norte-americana sugerindo que, historicamente, o modelo de gestão da ordem pública naquele país privilegia o corpo negro como ameaça e como alvo da punição. Para a autora, o contrato social se refere à realidade sócio-político-econômico-cultural na qual é mais vantajoso ser branco do que uma pessoa de cor, pois todas as normas são de fato normas brancas e a punição social é aceita e tolerada por ser aplicada principalmente aos negros (DAVIS, 2003).

As decisões judiciais desfavoráveis na vida das mulheres negras refletem essa «colonialidade da justiça». Cada vez mais homens brancos, jovens, oriundos da classe média alta, compõem o judiciário brasileiro e são eles que definem o futuro de vida e de morte das mulheres negras que ocupam a ponta do microtráfico de drogas. Para desvendar a lógica racial do sistema de justiça penal, é preciso ir além da descrição de sua composição demográfica, de seus desdobramentos nas narrativas judiciais e do entendimento de como o racismo tem espaço e atuação no imaginário e nas práticas institucionais. Os momentos etnográficos abaixo nos permitem localizar essas lógicas raciais na vida cotidiana das mulheres negras.

\section{Resultado e discussão}

Foram entrevistadas dez mulheres negras cumprindo pena na penitenciária Feminina de Sant'Ana na Capital Paulista. Na ocasião, foram observadas semelhanças nas suas trajetórias de vida: elas permaneceram privadas da liberdade antes da sentença condenatória; foram punidas como traficantes apesar de terem sido presas com pouca ou nenhuma quantidade de drogas, o que, em síntese, as caracterizariam como usuárias ou seriam absolvidas; todas são moradoras da periferia de São Paulo; são mães e estudaram até o ensino fundamental incompleto. As entrevistas transcritas aqui serão apenas de Rosa, Joana e Verônica, 7 as protagonistas das discussões nesse artigo. Elas representam as vítimas históricas de três processos intimamente ligados: a opressão por sua condição de cor, de gênero e de pobreza. A polícia aparece aqui como a ponta de um sistema de dominação de gênero e de raça em que o Estado penal aparece como seu principal promotor. Transcrevo parte da narrativa de D. Joana em entrevista no dia 05/10/2014:

7. Optei por oferecer nomes fictícios às mulheres para romper com a lógica burocrática que as reduzem a códigos numéricos nos seus processos e prontuários. Entendo que o nome fictício é uma tentativa de romper com a lógica desumanizante no sistema carcerário. 
Meu nome é Joana, mas aqui todo mundo me chama Febem. Eu peguei 7 anos de novo e tou aqui com minha filha, e agora ela teve um bebê, meu neto. Quando fui presa trabalhava como carroceira e morava nas ruas, embaixo do viaduto do Glicério. Eu tava na cracolândia e o policial me levou. Eu engoli três pedras de crack pra não ser presa. Já perdi as contas de quantas vezes vim pra cá. A primeira vez foi com 17 anos quando fui para a Febem e hoje tenho 49 anos. Já vivi mais aqui do que lá fora. O que eu quero hoje é poder ficar com minha filha mais perto e meu neto. O pai do menino a polícia matou e eles querem levar meu neto para a adoção, mas eu não vou deixar. Já falei com a Pastoral. Quando o juiz me deu os 7 anos eu gritei na cara dele. Eu disse que se eu fosse traficante não taria banguela, sem dente na boca, sem roupa, sem nada. Pior que eles só acredita na polícia mesmo. Me deu 7 anos como traficante, não aceito.

A crescente trajetória entre Fundação do Bem Estar do Menor - FEBEM, cadeias e penitenciárias fez com que outras mulheres presas e agentes penitenciários passassem a identificar D. Joana, não por seu nome, mas pelo apelido de «Febem». A instituição devorou seu nome e com ele parte da sua subjetividade. Entre «admissão» e progressão de regimes até a data da última prisão em 2014, D. Joana contava com, pelo menos, 11 passagens por presídios na capital, em Franco da Rocha, em Campinas e na Grande São Paulo. Todas as prisões foram por tráfico de drogas. Os policiais encontraram com ela 18 pedras de crack e $\mathrm{R} \$$ 540,oo. Embora a quantidade de droga apreendida e seu estado de penúria sugerisse que D. Joana fosse apenas uma vendedora localizada no andar de baixo do lucrativo comércio de drogas, ela teve a condenação de 8 anos, 10 meses e 20 dias de reclusão no regime inicialmente fechado, sob a alegação do juiz de que é uma «perigosa» traficante de drogas.

A voz do juiz, de acordo com ela, um jovem branco, condenou D. Joana porque, segundo a sentença, ela tem «caráter incorrigível e demonstra uma personalidade deformada e voltada à prática delituosa». Ela foi condenada devido a sua «temibilidade». A «temibilidade» de uma mulher negra, sem dentes, homossexual, carroceira e vivendo nas ruas da cidade encontra descompasso com a leniência jurídica sobre jovens de classe média envolvidos com o tráfico de drogas (ALVES y ALVES, 2015). Em entrevistas e compulsando o seu prontuário, D. Joana admitiu vender drogas para sustentar o seu vício, mas suas práticas «criminosas» não parecem sugerir um grau de periculosidade ao «corpo social» ameaçado pela impureza dos agentes do mal sugeridos pelo juiz branco. Na verdade, os termos subjetivos da sentença que indicam a suposta predisposição pessoal para o crime revela/esconde uma «episteme racial» (FANON, 1967) que nos remete aos discursos científicos do século XIX sobre as teorias raciais que tiveram em Nina Rodrigues seu maior expoente no Brasil ao tratar sobre criminalidade étnica. A sentença demonstra como nosso entendimento sobre crime, espaço e corpo marginais é baseado numa concepção racializada da lei e da ordem. Como alguns teóricos têm 
enfatizado, os conceitos de crime e desvio não são neutros: eles expressam ideologias de classe, pertencimento racial e de gênero (CIRINO, 2006; 1984).

Quando vi Rosa pela primeira vez, ela estava usando um véu branco e fazendo oração no grupo de assistência religiosa, apesar de relatar que antes da prisão não era religiosa naquela manhã era o dia de batismo. Estávamos todas na área de banho de sol e Rosa se aproximou e me perguntou: «É você a mulher que tá fazendo a pesquisa sobre tortura?». Rosa é apenas mais um nome, um rosto e uma cor nas estatísticas da população prisional feminina. O olhar cansado, os fios de cabelo brancos, apesar dos 36 anos de idade, a pele maltratada, as tosses insistentes durante a entrevista, tudo isso faz de Rosa uma mulher envelhecida, sofrida e inconformada. Nos primeiros encontros da entrevista, ela chorava ao falar sobre o difícil processo de adaptação ao cárcere. Os nossos encontros eram tensos e angustiantes. A gente sempre se despedia como se fosse a última vez. Ela me disse que passava os dias pensando na possibilidade de cometer suicídio com a filha nos dias de visitas familiares, pois tinha dificuldade de diálogo e compreensão entre ela e a equipe técnica.

Rosa é mais uma moradora da periferia da capital paulista. Foi ali na favela do Perus, onde foi presa por tráfico de drogas e torturada por 12 policiais militares. Ela relembra o dia da prisão e a ação terrorista da polícia, tão comum nas periferias das cidades brasileiras: «Eles tiraram minha roupa e eu fiquei nua na frente deles. Me afogaram num balde. Depois começaram colocar choque elétrico no meu seio, vagina e meu ânus e deram socos no meu ouvido e eu perdi a audição». Os laudos do Instituto Médico Legal ${ }^{8}$ comprovaram lesões com instrumentos contundentes, agressões físicas, otite crônica OD, diminuição auditiva e secreção no ouvido esquerdo de Rosa. Na ocasião da audiência, Rosa tentou convencer o juiz da tortura que sofreu, mas ele desqualificou sua voz e legitimou a ação policial com seguinte sentença:

Condeno a 08 anos de reclusão no regime fechado, único adequado a traficante de entorpecentes, dado que a prática do delito demonstra personalidade desajustada e perigosa, sem qualquer deferência ou mesmo compaixão pela incolumidade física e psíquica das inúmeras pessoas que, infelizmente, acabam seguindo pelas mãos de traficantes, a senda do uso de entorpecentes: personalidade, pois, incompatível com o convívio social» (extraído do processo de execução criminal).

Mais uma vez, os jargões jurídicos «personalidade desajustada e perigosa», «personalidade incompatível com o convívio social» demonstraram que, embora raça, como categoria biológica seja um tabu nos discursos punitivos, juízes adaptam, conscientes ou inconscientemente, os discursos racializados em pressupostos subjetivos para justificar 
punições e criminalizar os grupos vulneráveis. Em outro momento dos nossos encontros, Rosa fala da dor de ter a sua vida roubada. Aqui, o Estado penal aparece como um ladrão que rouba sonhos, sequestra corpos e mata a existência plena.

Sabe, Dina, hoje me doeu muito encontrar três fios de cabelo brancos em mim, percebi que estou ficando velha e que os anos estão passando. Se eu acreditava em outro mundo hoje não acredito. Hoje o que me dá força para levantar é saber que tenho minha filha (Rosa, entrevista dia 18/18/2014).

Encontrei, nos prontuários de Rosa, o registro de diversas tentativas fracassadas de diálogo entre a equipe técnica do presídio e ela. Ironicamente tais anotações referem-se ao «quadro evolutivo da reeducanda» e evidenciam a ineficácia, seja por parte da equipe técnica, seja por parte da direção do presídio, em lidar com a situação de Rosa e ouvir suas constantes queixas sobre as sequelas das torturas sofridas. Nas anotações do prontuário médico-psicológico (datado de abril de 2014), fica evidente a impossibilidade de uma empatia com o sofrimento de Rosa, reduzidas aos termos técnico-burocráticos da linguagem estatal:

02/04/14 - Reeducanda se mostra muito angustiada, triste e perdida por estar presa. Diz que não está conseguindo dormir e chora todos os dias.

o9/04/14 - Reeducanda afirma não precisar de atendimento psicológico e se recusa a conversar.

30/04/14 - Se recusa a falar.

30/04/14 - Muda de ideia e fala da angústia e inconformismo com a prisão já que não cometeu nenhum crime. Informa que os remédios acabaram e está aguardando por $\mathrm{O} 2$ semanas o atendimento com o psiquiatra.

07/05/14 - Doente (febre).

14/05/14 - Reeducanda afirma angústia por estar sem os remédios e inconformismo pela prisão.

21/05/14 - Doente (Vômito).

28/o5/14 - Não quer conversar.

04/06/14 - Desistiu

A resistência de Rosa nos encontros com a equipe técnica da unidade, revela não apenas que as possíveis tentativas de diálogo fracassaram, como também evidencia a sua frustração com um regime de direitos que toma como verdade absoluta a palavra do juiz, e deixa pouca ou nenhuma possibilidade de justiça para aqueles vistos como 
perigosos e puníveis. Neste sentido, o trabalho da equipe limita-se a fazer simples e superficiais anotações no prontuário como parte da burocracia penal estatal. Os psicólogos, assistentes sociais e demais funcionários incorporam o Estado penal em suas práticas rotineiras, o que bem delineou Foucault em suas críticas incisivas aos regimes de (bio) poder (FOUCAULT,1987). Aprisionar corpos, conformá-los a aparatos disciplinários, produzir subjetividades submissas, aí reside o papel da burocracia estatal prisional.

Nos encontros com Rosa, sua explicação sobre a resistência aos atendimentos foi descrita na seguinte resposta: «A psicóloga e o psiquiatra estavam tentando fazer eu viver presa». Na visão de Rosa, ensinar a viver presa é a missão dos profissionais do sistema prisional. É preciso aprender as regras do sistema, não apenas no que diz respeito à convivência com as outras mulheres presas, mas também os códigos do poder, como abaixar a cabeça frente à autoridade prisional, colocar as mãos para trás em sinal de constante submissão, dar ao psicólogo/a, agente carcerário/a, assistente social, estagiários o tratamento de «senhor/senhora/doutor/doutora».

Há todo um saber físico-penal que é inscrito na ordem do discurso e no corpo das mulheres presas, como um símbolo da expressão de soberania do Estado sobre os corpos marcados. No caso de Rosa, a condenação severa de 8 anos de reclusão, a perda da audição e as marcas dos choques elétricos no corpo, são uma espécie de código jurídico da dor (FOUCAULT, 1987) e de inscrição corporal da soberania estatal sobre seu corpo de mulher negra.

Como se aprende a viver na prisão? Talvez o uso compulsivo (e cada vez mais indiscriminado) de medicamentos psicotrópicos seja uma expressão do controle sobre os pensamentos e as vontades das pessoas encarceradas, e seja um dos instrumentos mais utilizados para a convivência no interior do sistema. Esta é outra dimensão conhecida, mas pouco explorada pelas ciências sociais, que revela, contudo, os desdobramentos do Estado penal e seus impactos no que se poderia chamar de «poder macabro» do Estado em produzir terror corporal (corpos puníveis, vazios, assombrados, psicologicamente destruídos). Ele ocupa as entranhas, saqueia subjetividades, destrói corpos e ocupa a intimidade da vida.

O relato de Verônica dá uma dimensão do teatro da dominação em que se converte o espaço prisional:

É fila, mãos na cabeça, tem a linha amarela, é disciplina, palavra de ordem. Quando eu cheguei em Franco da Rocha foi a maior humilhação, eles mandam a gente olhar pra baixo, mãos pra trás. Tratam a gente como bicho do mato. Discriminação total. Se vocêtá doente, a saúde é uma merda. Te deixa numa sala trancada até ser atendido e quando atende fala que tu não tem nada, que é frescura. (entrevista dia 22/08/2014).

A prisão de Verônica nos ajuda a desvendar alguns «registros escondidos» das tipologias criminais e do papel das categorias de raça e gênero na construção de corpos 
puníveis no sistema de justiça. Na entrevista ela relatou que «enquanto estava presa, sua mãe faleceu e os dois filhos foram levados para o abrigo e colocados à disposição do juizo para adoção». Verônica tem 29 anos de idade, estudou até a terceira série, é negra e trabalhou toda a sua vida como empregada doméstica. Segundo ela «fui presa por roubo de um prestobarba e de $R \$ 41,00$, em uma farmácia. Mais eu não tava lá dentro não. Meu namorado que entrou para roubar. Ele estava com uma chave de fenda e quando a polícia veio me levou sem nem me ouvir». Tal qual Joana e Rosa, Verônica faz parte de uma tendência no sistema de justiça penal de encarceramento de mulheres negras e pobres por pequenos delitos ou por sua «proximidade» com o chamado «mundo do crime». Também na sua sentença condenatória percebe-se a hiper-vigilância estatal a família e revela o que chamo aqui de obsessão por punir. O que justifica tal regime patológico é o senso-comum de que algumas geografias e alguns corpos são inerentemente fora da lei. A destruição do lar bem pode ser um sinal para entender como o estado produz fábulas de justiça e de paz enquanto destrói vidas metafórica e literalmente:

Condeno a ré a 7 anos 3 meses e 3 dias de reclusão e a perda do pátrio poder dos filhos menores e a inclusão e casa de adoção. A ré apresenta personalidade voltada para o crime e portanto, não tem condições de ter convivência com seus filhos, ensejando assim a majoração da reprimenda (Execução criminal 834547)

A sentença não pune apenas Verônica, mas criminaliza a maternidade negra. Comumente mulheres negras com filhos são vistas como promíscuas, dependentes do Bolsa-Família, parideiras, moralmente corruptas e com útero de fabricar marginais. Pensadoras ativistas como Patrícia Hill Collins (2000) têm chamado apropriadamente de «controle da imagem» das mulheres negras. Essas estratégias de controle de imagem -Collins analisa as representações patológicas da mulher negra como a servil mammy e a sexualmente depravada Jezebel-pode ser vista não apenas nas re-atualizações diárias televisivas do lugar subalterno da mulher negra, mas, principalmente, nas narrativas judiciais racistas que justificam as punições no sistema de justiça penal. A punição das mulheres negras não se resume ao aprisionamento dos seus corpos, portanto. Vistas como incapazes de gerir suas famílias, ou como perigo ao desenvolvimento de crianças «boas», não raras vezes os juízes optam por revogar a guarda de seus filhos, oferecê-los para adoções ou aprisioná-los em instituições prisionais eufemisticamente chamados de centros de ressocialização.

Analisar a colonialidade da justiça como fator histórico e re-atualizado cotidianamente com impacto cruel na vida destas mulheres e seus familiares, é fundamental para entender a hipervisibilidade que seus corpos ocupam no sistema penal. Se, por um lado, as entrevistadas são invisibilizadas para o mercado de consumo e de trabalho-é na aplicação e administração da justiça criminal onde se manifesta de forma hiper-visível a produção de corpos puníveis. 
Os relatos das entrevistadas, as narrativas penais nas sentenças e a resistência ao cárcere frente aos servidores judiciais, chamam a atenção para a condição paradigmática da mulher negra diante do Estado penal. $\mathrm{O}$ ato de resistir ao «sistema» por meio da denúncia e do silêncio pode ser lido em conjunto com um outro ato explícito de confrontação e desnudamento do Estado carcerário. Se o Estado produz fábulas/mitos de justiça e verdades, Rosa, Verônica e Joana desmistificam tais narrativas ao utilizar o corpo doido e brutalizado como veículo de resistência à ordem patriarcal. Em um dos nossos encontros, Rosa me explicou um gesto ilustrativo da sua condição. Durante a audiência com o juiz, e depois de tentativas frustradas de denunciar as torturas inscritas em seu corpo, ela suspendeu a blusa mostrando os seios e gritando: «fui torturada, aqui estão as marcas». Ao tentar sensibilizar «eles» da sua existência político-corporal, Rosa repetia, sem saber, um gesto simbólico da abolicionista Sojouner Truth, que expôs os seios ao público como tentativa de sensibilizar as mulheres brancas sobre a existência, tanto biológica quanto política, das mulheres negras nos Estados Unidos escravista. Embora em contextos diferentes, ambos os gestos podem ser lidos como estratégias de reafirmar a humanidade e existência política de um grupo social que é civilmente quase vivo, portanto, ainda socialmente morto. Afinal, como Sojourner e como tantas mulheres negras encarceradas, Rosa, Verônica e Joana são mulheres, mas são negras.

\section{Conclusão}

Ser negra, pobre e mulher são fatores decisivos que influenciam as decisões judiciais na aplicação da lei penal e no encarceramento em massa. Entender o legado do sistema da escravatura no Brasil, como constituinte do atual sistema penal pode se revelar importante meio para uma democratização da Justiça. Mais ainda, reconhecer a especificidade da mulher negra encarcerada é importante para perceber como tais categorias produzem um complexo e difuso sistema de privilégios e de desigualdades que se refletem na realidade carcerária em São Paulo, especialmente no que se refere às mulheres negras encarcerada. A igualdade formal preconizada pela Constituição Federal garante a todas as pessoas os direitos fundamentais e sociais de forma isonômica. Mas, o poder judiciário reconhecer a existência do racismo institucional é um passo fundamental, pois mesmo na igualdade formal, em que todos e todas são iguais perante a lei, existem mecanismos «invisíveis» de discriminação que fazem com que algumas pessoas sejam menos iguais ou menos humanas, ou não humanas. As práticas rotineiras de policiamento de comunidades predominantemente negras e o crescimento nas estatísticas prisionais de mulheres negras, bem podem ser lidos como um diagnóstico da insidiosa persistência do racismo e da colonialidade da justiça criminal no Brasil contemporâneo. 


\section{Referências}

ADORNO, S. (1995). «Discriminação racial e justiça criminal em São Paulo». Novos Estudos. CEBRAP, n. 43, pp. $45-63$.

ALVES, D. (2015). «Rés negras, Judiciário branco: uma análise da interseccionalidade de gênero, raça e classe na produção da punição em uma prisão paulistana». Dissertação de Mestrado em Ciências Sociais. São Paulo, Universidade Pontifícia Católica de São Paulo.

ALVES, J Y ALVES, D. (2015). «Drugs and drug control and Brasl».In Anita Kalunta-Crumpton, Pan-African Issues in Drugs and Drug Control: An International Perspective. London: Assage Editora.

ALVES, J. (2014). «On mules and bodies: black captivities in the Brazilian racial democracy». Critical Sociology, OnlineFirst, pp. 1-20.

BATISTA, N. (2002). «Matrizes ibéricas do sistema penal brasileiro». Coleção Pensamento Criminológico, V. 1. n. 5, Rio de Janeiro, Revan.

BRASIL. (2007). «Retratos da desigualdade: gênero e raça». Brasília, Instituto de Pesquisa Econômica Aplicada - IPEA/PNAD. Disponível em: http://www.ipea.gov.br/retrato/pdf/primeiraedicao.pdf. Acesso em: 25 jun. 2014.

BRASIL. (2013). «Censo do Poder Judiciário: Vetores Iniciais e dados estatísticos». Conselho Nacional de Justiça - Brasília: CNJ.

BRASIL. MINISTÉRIO DA JUSTIÇA. (2010/2015). Departamento Penitenciário Nacional. Brasília, DEPEN. Disponível em: http://portal.mj.gov.br/data/Pages/MJC4D50EDBPTBRIE.htm. Acesso em: 12 maio 2016.

BRASIL. MINISTÉRIO DA JUSTIÇA. (2016). «Convenção Internacional sobre a eliminação de todas as formas de discriminação racial». Disponível em: http://www.mj.gov.br/sedh/ct/legis_intern/-conv__int_eliminação_disc_racial.htm. Acesso em: 19 abr. 2014.

BRAUNSTEIN, H. R. (2007). «Mulher encarcerada: trajetória entre a indignação e o sofrimento por atos de humilhação e violência». Dissertação de Mestrado em Educação. São Paulo, Universidade de São Paulo.

CARNEIRO, S. (1995). «Gênero, raça e ascensão social». Estudos Feministas, v.3, n. 2, ano 3, pp. 544-552.

CERNEKA, H. A. (2009). «Homens que menstruam: considerações acerca do sistema prisional às especificidades da mulher». Veredas do Direito, v. 6, n. 11, pp. 61-78.

CERNEKA, H. A. (2010). «Encarceramento em massa: lembrando que a massa tem nomes, famílias e histórias». Revista PUC Viva, v. 39. São Paulo.

CERNEKA, H. A. (2013). «Presos e presas provisórios: Relato de pesquisa e intervenção jurídica realizada em dois presídios de São Paulo em 2010 e 2011. Tecer justiça, São Paulo. 
CIRINO, J. (2006). «A criminologia Radical». Curitiba, Lumen Juris.

COLLINS, P. H. (200o). «Black feminist thought: knowledge, consciousness, and politics of empowerment». New York, Routledge.

CRENCHAW, K. (1995). «Mapping the margins: Intersectionality, Identity, Politics, and Violence against Women of Color». Critical Race Theory, New York, The New Press.

DAVIS, A. (2003). «Are Prison Obsolete»? New York, Open Media/Seven Stories Press.

DAVIS, A. (2009). «A democracia da abolição: para além do império das prisões e da tortura». Rio de Janeiro, DIFEL.

FANON, F. (1967). Black Skin, White Masks. Originally published in 1952, translated by Charles Lam Markmann. New York: Grove Press.

FOUCAULT, M. Verdade e Poder. Microfísica do Poder. Rio de Janeiro: Graal, 2004.

FOUCAULT, M. (1987). «Vigiar e punir: nascimento da prisão». Petrópolis, Vozes.

FREIRE, P (1996). «Pedagogia da autonomia: saberes necessários à prática educativa». São Paulo, Paz e Terra.

GONZALEZ, L. (1983). «Racismo e sexismo na cultura brasileira». Revista Ciências Sociais hoje, n. 2, pp. 223-244.

GROSFOGUEL, R. (2007). «Dilemas dos estudos étnicos norte-americanos: multiculturalismo identitário, colonização disciplinar e epistemologias descoloniais». Ciência e cultura, v. 59, n. 2, pp. 32-35.

HALE, C. (2001). «What is activist research?». Social Science Research Council: Items \& Issues, v. 2, n. $1-2$, pp. $13-15$.

IBCCRIM - INSTITUTO BRASILEIRO DE CIÊNCIAS CRIMINAIS. (2003). «Mulheres negras: as mais punidas nos crimes de roubo». Boletim IBCCRIM, n. 125, pp. 1-4.

ONU. (2016). Relatório mundial 2015: Brasil. «Condições das prisões, torturas e maus-tratos a detentos». Disponível em: https://www.hrw.org/pt/world-report/2015/country-chapters/268103\#3ea6cd. Acesso em: 26 jun. 2014 .

PASSETI, E. (2006). «Ensaio sobre um abolicionismo penal». Verve, v. 9, pp. 83-114.

PEREIRA, B. P. (2011). «De escravas a empregadas domésticas - A dimensão social e o "lugar" das mulheres negras no pós- abolição». In: XXVI SIMPÓSIO NACIONAL DE HISTÓRIA ANPUH: 50 anos, São Paulo. Anais do XXVI simpósio nacional da ANPUH - Associação Nacional de História.

PRADO, A. C. (2003). «Cela forte mulher». São Paulo, Labortexto Editorial.

SADENBERG, C. M. B. (2002). «Da crítica feminista à Ciência a uma Ciência Feminista?» (org). $\mathrm{Fe}$ minismo, Ciência e Tecnologia. Salvador, NEIM-UFBA/REDOR, pp. 89-120. 
SEGATO, R. (2007). «El color de la cárcel en América Latina: apuntes sobre la colonialidad de la justicia en un continente em desconstrucción». Revista Nueva Sociedad, n. 208, pp. 142-161.

SUDBURY, J. (2005). «Global Lockdown: Race, Gender, and the Prison-Industrial Complex». New York, Routledge.

WACQUANT, L. (2001). «As prisões da miséria». Rio de Janeiro, Jorge Zahar.

VARGAS, J. C. (2008). Activist scholarship: limits and possibilities in times of black genocide. In engaging contradictions: theory, politics and methods of activist scholarship. Berkeley: University of California Press.

ZAFFARONNI, R.; BATISTA, N.; SLOKAR, A. W. (2003). «Direito Penal Brasileiro», Teoria Geral do Direito Penal. V.1, Rio de Janeiro, Revan. 